\title{
Структурные и газочувствительные характеристики тонких полупроводниковых пленок PdO различной толщины при детектировании озона
}

\author{
(C) С.В. Рябцев ${ }^{1}$, Д.А.А. Гхариб ${ }^{1}$, С.Ю. Турищев ${ }^{1}$, Л.А. Обвинцева ${ }^{2}$, А.В. Шапошник ${ }^{3}$, Э.П. Домашевская ${ }^{1}$ \\ ${ }^{1}$ Воронежский государственный университет, \\ 394006 Воронеж, Россия \\ ${ }^{2}$ Научно-технологический центр уникального приборостроения Российской академии наук, \\ 117342 Москва, Россия \\ ${ }^{3}$ Воронежский государственный аграрный университет, \\ 394087 Воронеж, Россия \\ E-mail: ryabtsev@phys.vsu.ru
}

Поступила в Редакцию 24 мая 2021 г.

В окончательной редакции 30 мая 2021 г.

Принята к публикации 30 мая 2021 г.

Пленки $\mathrm{PdO}$ были получены методом термического напыления металлического палладия толщиной 30 и 90 нм с последующим его окислением на воздухе при различных температурах. Оксидные пленки PdO охарактеризованы методами просвечивающей электронной микроскопии и дифракции быстрых электронов. Получены данные о полупроводниковых свойствах и газовой чувствительности к различным концентрациям озона в воздухе. Установлены оптимальные температурные условия окисления пленок, которые обеспечивают их однородный фазовый состав и отсутствие электрических шумов при детектировании газов. Предложен и обоснован механизм появления электрических шумов в ультратонких пленках, связанный с их фрагментированием в процессе окислительного отжига. Показана возможность детектирования полупроводниковыми пленками $\mathrm{PdO}$ примесей озона в воздухе ниже предельно допустимой концентрации.

Ключевые слова: тонкие пленки оксида палладия, фазовый состав, электрические шумы, газосенсорные свойства.

DOI: $10.21883 /$ FTP.2021.11.51557.9684

\section{1. Введение}

В последнее время приобретает широкое распространение использование озона в технологических целях, например, для обеззараживания воды в водопроводах, бассейнах, аквапарках, очистки стоков, отбеливания бумаги и т.д. Так как озон нестойкий газ, его обычно получают с помощью специальных генераторов непосредственно на местах его использования. Вместе с тем озон является одним из самых токсичных газов. Предельно допустимая концентрация (ПДК) озона в воздухе рабочей зоны составляет - $0.1 \mathrm{M \Gamma} / \mathrm{M}^{3}$ или $\sim 50 \mathrm{ppb}\left(1 \mathrm{ppb}-10^{-7}\right.$ об\%). Поэтому для обеспечения техники безопасности на станциях получения и применения озона необходимо проводить непрерывный и многоточечный контроль его содержания в окружающем воздухе. В большинстве случаев эта задача решается с помощью приборов, основанных на оптическом принципе детектирования. Эти приборы имеют ряд недостатков: высокую стоимость и энергопотребление, а также они сложны в обслуживании. Кроме того, они обеспечивают анализ озона только в одной точке, где расположен оптический датчик. Альтернативой являются приборы на основе полупроводниковых сенсоров резистивного типа [1]. Основные преимущества сенсорных приборов заключаются в отсутствии расходных материалов, возможности многоточечного и непрерывного мониторинга воздуха рабочей зоны. Датчики таких приборов изготавливаются на основе полупроводниковых оксидов. Выбор материала газочувствительного слоя, как и технология его изготовления, во многом определяют характеристики сенсора. Наиболее часто применяется золь-гель технология, которая обеспечивает получение высокоразвитой поверхности, максимально доступной для адсорбции газов. В представленной работе рассмотрена тонкопленочная технология вакуумного напыления газочувствительных слоев, так как она хорошо сочетается с уже хорошо отработанными технологиями микроэлектроники, что обеспечивает существенное снижение себестоимости газоаналитических приборов.

Чаще всего для детектирования озона используют оксиды $\mathrm{WO}_{3}, \mathrm{In}_{2} \mathrm{O}_{3}, \mathrm{SnO}_{2}, \mathrm{ZnO}$, как индивидуальные, так и с различными добавками. В настоящей работе был применен новый сенсорный оксидный материал $\mathrm{PdO}$, впервые предложенный для анализа озона в наших предыдущих работах [2-5].

Цель настоящей работы - установление особенностей газочувствительных свойств тонких пленок $\mathrm{PdO}$ различной толщины и оптимизация технологии их изготовления, которая обеспечивает возможность детектирования концентраций озона ниже уровня ПДК. 


\section{2. Экспериментальная часть}

Пленки $\mathrm{PdO}$ были получены путем термического напыления металлического Pd на различные подложки с последующим их окислением на воздухе. Для оптических исследований использовались стеклянные пластины, для исследований на просвечивающем микроскопе (ПЭМ) использовались подложки из монокристаллического $\mathrm{KCl}$ с подслоем аморфного углерода.

Металлический $\mathrm{Pd}$ наносился на подложки со скоростью $\sim 1$ нм/мин. Скорость нанесения Pd была определена при исследовании поперечного скола пленок на монокристаллической кремниевой подложке с помощью сканирующего электронного микроскопа. Рассчитанные толщины рабочих образцов составляли 30 и 90 нм. Полученные металлические пленки были отожжены в атмосфере воздуха в течение 1 ч при температурах 240 , 400 и $600^{\circ} \mathrm{C}$. Затем была проведена их характеризация.

Оптические исследования спектров пропускания были проведены на волоконно-оптическом спектрометре Ocean Optics. Фазовый состав и микроструктура пленок были исследованы методами дифракции быстрых электронов (ДБЭ) и микроскопии на ПЭМ Karl Zeiss Libra 120. Исследования электрофизических и газосенсорных свойств пленок проводили на специальных поликоровых подложках $\left(\mathrm{Al}_{2} \mathrm{O}_{3}\right)$ со встроенными Pt электродами для измерения сопротивления пленок. С другой стороны подложек был нанесен Pt нагреватель в виде меандра, который служил одновременно и датчиком температуры. Температура сенсоров поддерживалась в экспериментах с точностью $1{ }^{\circ} \mathrm{C}$.

Для получения различных концентраций озона в воздухе использовался генератор озона ГС-024-25 (АО ,ОПТЭК

\section{3. Результаты и их обсуждение}

\section{1. Ширина запрещенной зоны и структурные характеристики тонких пленок PdO различной толщины}

В соответствии с литературными данными $\mathrm{PdO}$ является полупроводниковым оксидом $p$-типа с шириной запрещенной зоны 2.2-2.7 эВ [6-8]. Полупроводниковый характер изучаемых в настоящей работе пленок подтверждается методами оптической спектроскопии. Спектры пропускания пленок $\mathrm{PdO}$ имеют характерный для полупроводниковых материалов вид с резким уменьшением пропускания вблизи фундаментального электронного перехода зона-зона $E_{v}-E_{c}$. В координатах Тауца (Tauc) $E-(\alpha d h v)^{2}$ была определена ширина запрещенной зоны $E_{g}$ пленок $\mathrm{PdO}$ (рис. 1). Экстраполяция прямых, проведенных к прямолинейным участкам оптических спектров на ось абсцисс, дает величины $E_{g}=2.27$ эВ и $E_{g}=2.21$ эВ (рис. 1) для пленок $\mathrm{PdO}$ толщиной $\sim 30$ и $\sim 90$ нм соответственно. Полученные значения

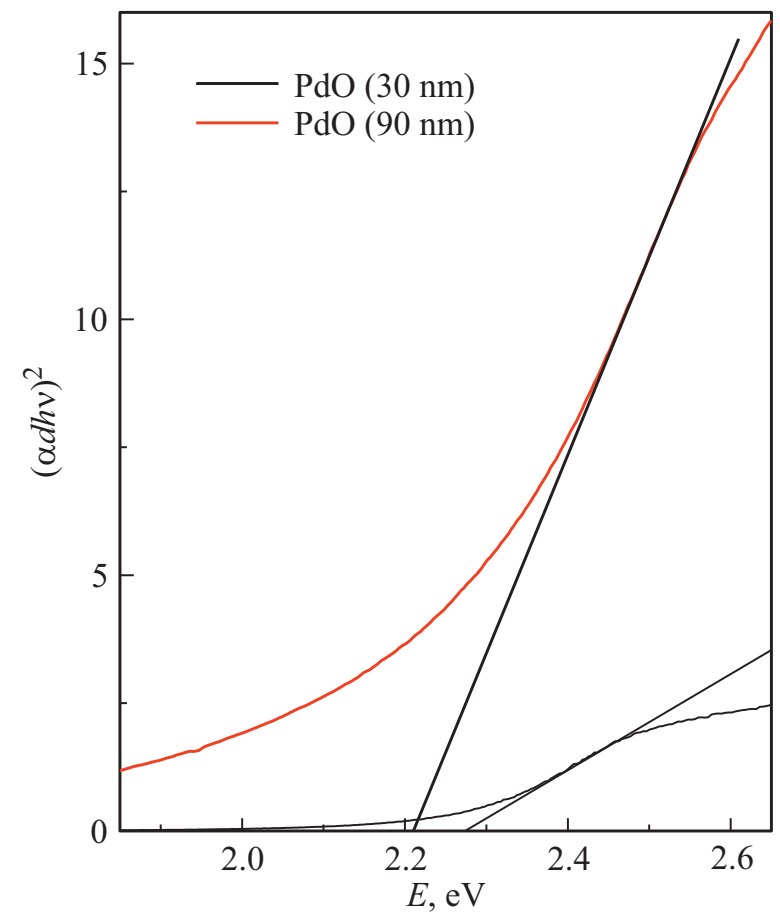

Рис. 1. Оптические спектры пленок $\mathrm{PdO}$ с толщиной 30 и 90 нм в координатах Тауца.

$E_{g}$ полностью соответствуют известным литературным данным для этого оксида [6-8].

Обе пленки металлического Pd окислялись в одинаковых условиях при $550^{\circ} \mathrm{C}$ в течение 1 ч. Небольшие отличия значений $E_{g}$ связаны с толщинами пленок. Мы предполагаем, что более толстая пленка имеет больше дефектов, чем тонкая, поэтому хвосты локализованных состояний в запрещенной зоне имеют большую плотность, что несколько уменьшает графически рассчитанную величину $E_{g}$.

На рис. 2 и 3 приведены электронограммы и ПЭМизображения пленок Pd на разных стадиях их окисления. Анализ электронограмм показал, что исходные пленки (см. рис. 2, $a$, и 3, $a$ ) представляют собой металлический палладий без видимых следов оксидных фаз. Такой же фазовый состав имеют и пленки, отожженные в атмосфере воздуха при $240^{\circ} \mathrm{C}$ (PDF card 00-041-1043 [9]).

Дальнейшее увеличение температуры отжига пленок $\mathrm{Pd}$ в атмосфере воздуха при 400 и $600^{\circ} \mathrm{C}$ приводит к формированию тетрагональной оксидной фазы $\mathrm{PdO}$ (PDF card 00-041-1107 [9]). При этих температурах отжига фаза металлического палладия в пленках уже не обнаруживается методом ДБЭ, т.е. процесс окисления палладия полностью завершается, и пленка приобретает однофазный состав тетрагонального PdO.

Одной из особенностей процесса окислительного отжига тонкой пленки толщиной 30 нм является укрупнение кристаллитов в процессе отжига как в пленке $\mathrm{Pd}$ (рис. 2,b), так и в пленках $\mathrm{PdO}$ (рис. 2, $c$ и $d$ ). Пленки при этом теряют свою первоначально сплошную 

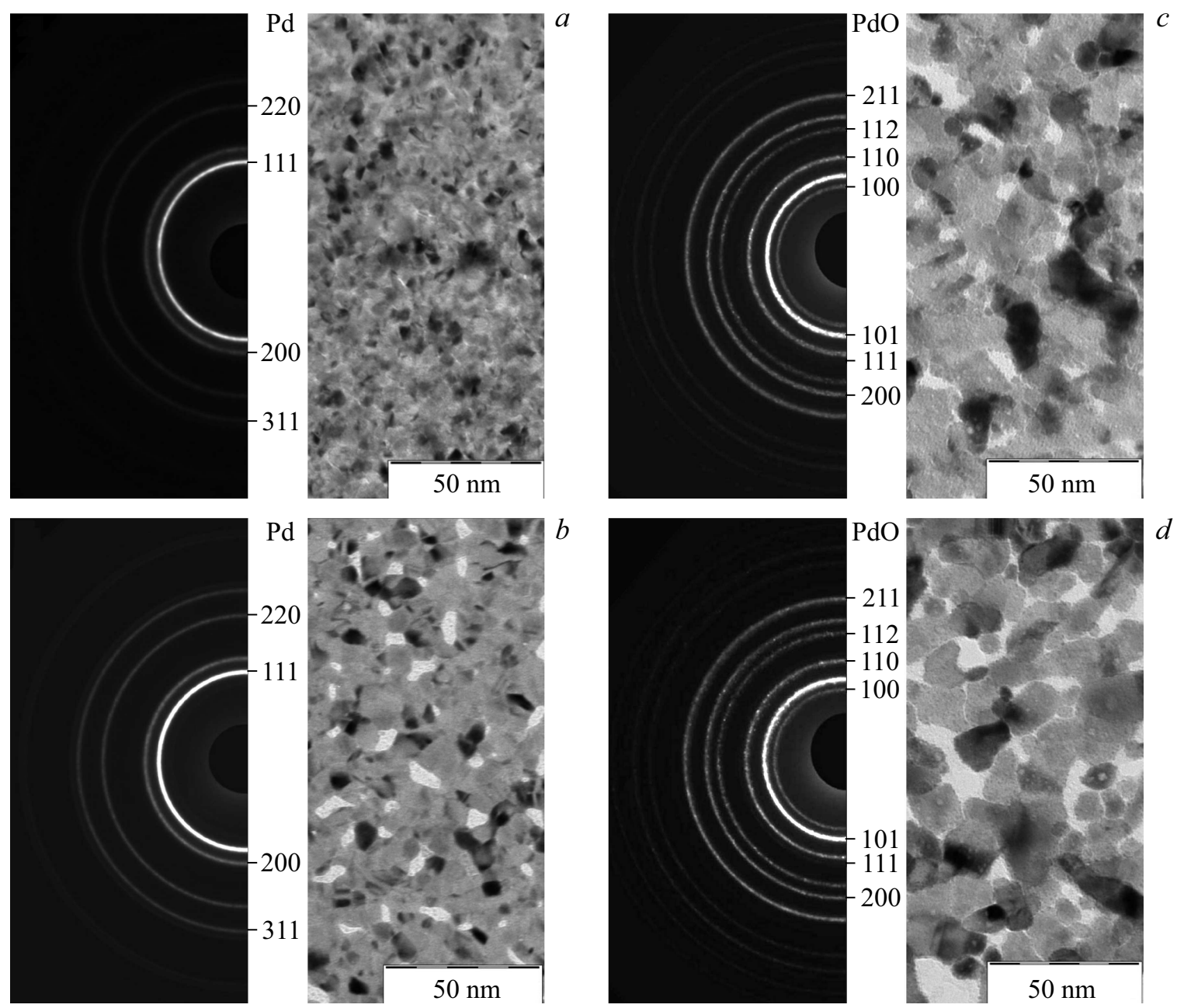

Рис. 2. Электронограммы и ПЭМ-изображения исходной пленки $\mathrm{Pd} \sim 30$ нм $(a)$ и пленок, отожженных при температурах $240(b)$, $400(c)$ и $600^{\circ} \mathrm{C}(d)$.

структуру. Рост размеров кристаллитов и образование разрывов в пленке происходит пропорционально увеличению температуры отжига. Такая собирательная рекристаллизация существенно влияет на электрофизические свойства пленок. В процессе окислительного отжига пленок, нанесенных на тестовые структуры, регистрировалось их текущее сопротивление, которое монотонно росло при увеличении температуры. Главным образом, это связано с окислением металлического палладия до полупроводникового оксида, имеющего более высокое сопротивление.

Важным моментом в процессе отжига было появление при температурах $>550^{\circ} \mathrm{C}$ электрических шумов, которые, судя по данным микроскопических исследований (рис. 2), непосредственно связаны с фрагментацией тонких пленок. Мы предполагаем, что за счет прогрессирующей фрагментации пленки ухудшается качество контактов между кристаллитами, что и является причиной электрических шумов. Выше $600^{\circ} \mathrm{C}$ уровень шумов, так же как и сопротивление пленок, резко возрастают. При температуре $650-700^{\circ} \mathrm{C}$ фрагментация пленок завершается, что приводит к полному исчезновению электропроводности пленок.

Таким образом, для пленок $\mathrm{PdO}$ толщиной $30 \mathrm{HM}$ оптимальная температура отжига не должна превышать $550^{\circ} \mathrm{C}$, что, с одной стороны, обеспечивает однофазный состав пленок, а с другой - отсутствие электрических шумов, которые мешают проведению точных резистивных измерений.

На рис. 3 приведены электронограммы и ПЭМ-изображения более толстой исходной пленки $\mathrm{Pd}$ толщиной 90 нм и тех же пленок, отожженных на воздухе при температурах 240,400 и $600^{\circ} \mathrm{C}$. Закономерности, связанные с фрагментацией пленок $\mathrm{PdO}$, сохраняются и в этом случае, но выражены в гораздо меньшей степени. После окислительного отжига в пленках появляются отдельные несплошные участки. С увеличением температуры отжига также наблюдается укрупнение микрокристаллитов. Отличие этих пленок от рассмотренных выше заключается в том, что появление шумов электропроводности наблюдается при более высокой температуре окислительного отжига, $>650^{\circ} \mathrm{C}$. 

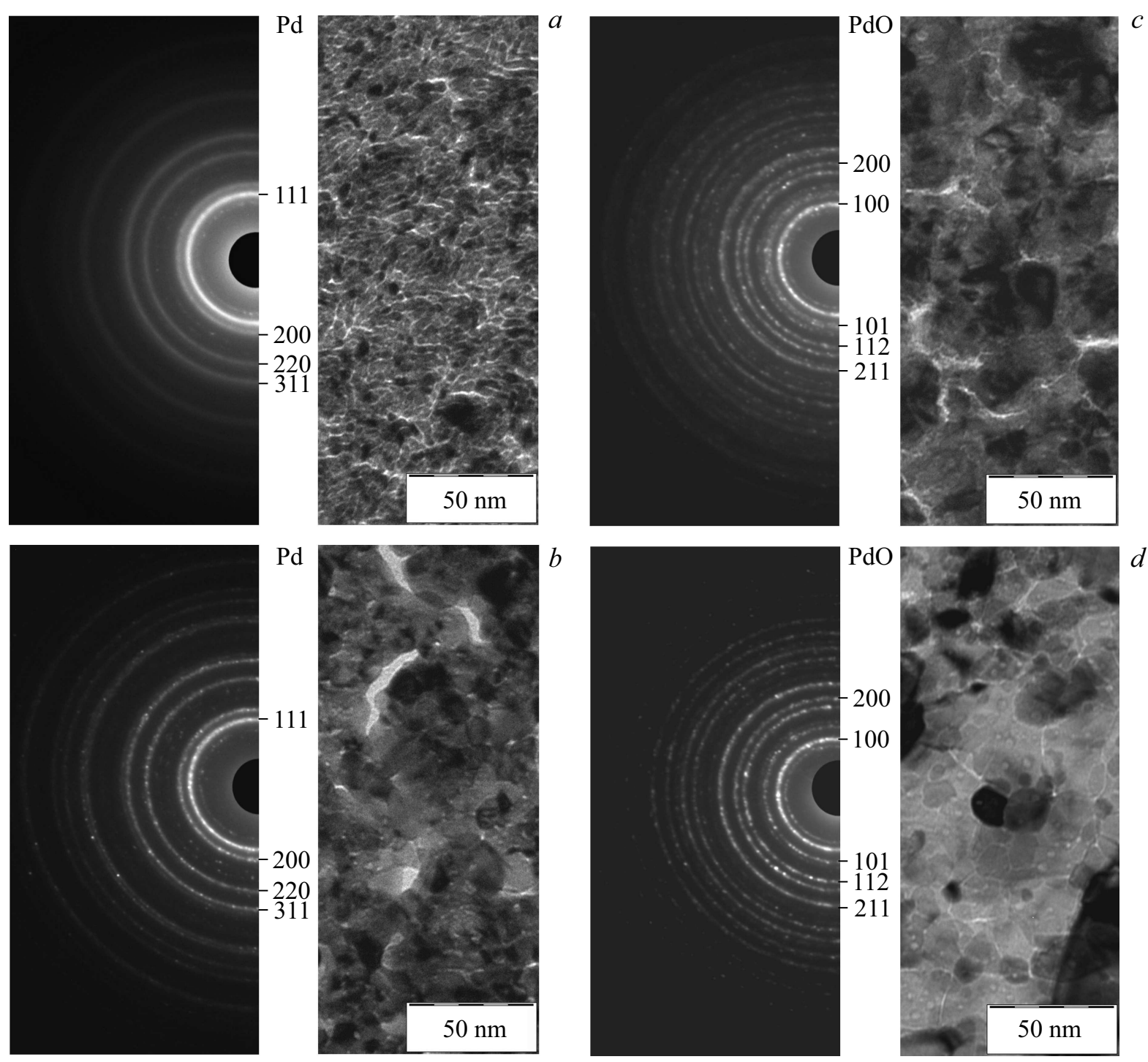

Рис. 3. Электронограммы и ПЭМ-изображения исходной пленки $\mathrm{Pd} \sim 90$ нм $(a)$ и пленок, отожженных при температурах $240(b)$, $400(c)$ и $600^{\circ} \mathrm{C}(d)$.

Проводимость $p$-типа для пленок РdO была установлена нами ранее при исследовании эффекта Зеебека для тонкопленочных образцов [4]. Этот факт подтверждается также и характером резистивного отклика пленок $\mathrm{PdO}$ в среде озона - газа окислителя (рис. 4). Сопротивление пленок $\mathrm{PdO}$, как и ожидалось для $p$-типа полупроводника, уменьшается в окислительной среде озона (рис. 4), что соответствует известным механизмам сенсорного отклика [10].

\section{2. Газочувствительные свойства пленок PdO различной толщины}

Газочувствительные свойства пленок PdO были изучены при различных концентрациях озона $25,55,90$ и $250 \mathrm{ppb}$ в воздухе. Изучаемые в работе пленки имеют различные значения сопротивления, поэтому для кор- ректного сравнения их сенсорных свойств необходимо представлять данные в относительных единицах $\Delta R / R_{0}$, где $\Delta R-$ разница значений сопротивления сенсора в воздухе и в среде, содержащей озон, а $R_{0}-$ сопротивление пленок в чистом воздухе. Рабочая температура пленок PdO в экспериментах по детектированию озона составляла $150^{\circ} \mathrm{C}$. Резистивный отклик пленок $\mathrm{PdO}$ c различной толщиной 30 и 90 нм представлен на рис. 4.

Сравнение резистивного отклика в пленках PdO разной толщины на рис. 4 показывает, что более толстая пленка имеет меньший отклик в области больших концентраций озона и несколько худшую кинетику релаксации сигнала сенсора после продувки измерительной ячейки воздухом без примесей озона. Кроме того, резистивный отклик пленки $\mathrm{PdO}$ (90нм) имеет меньшую крутизну (рис. 5), что ухудшает точность количественного анализа озона в широком диапазоне 
концентраций. Результаты указывают на более низкую адсорбционную емкость сенсора по отношению к озону вследствие того, что объемные области более толстого

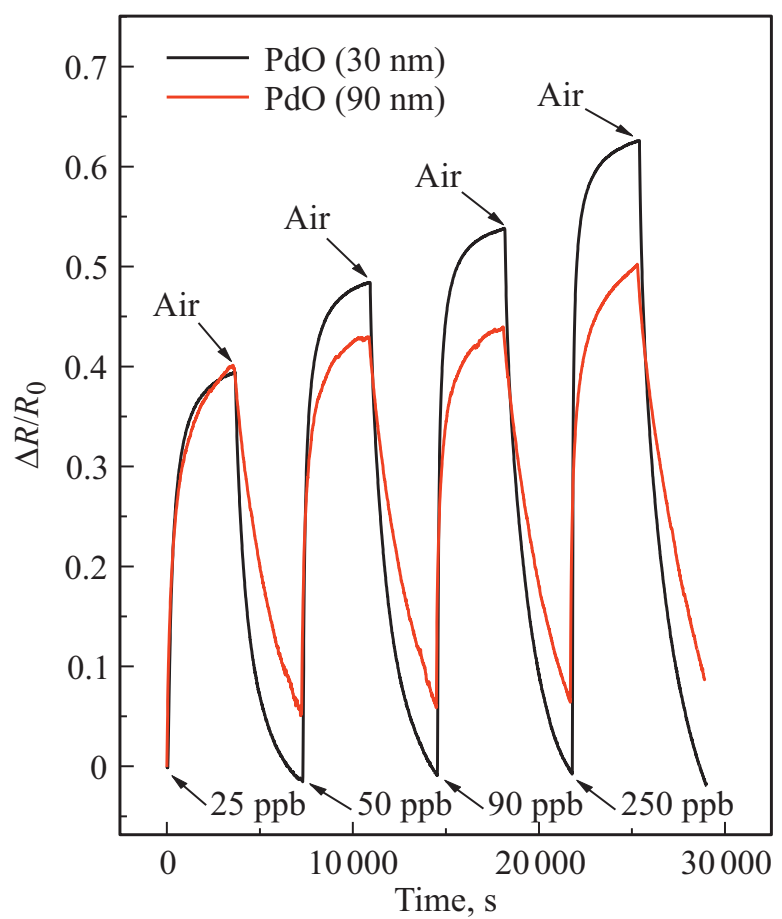

Pис. 4. Резистивный отклик пленок $\mathrm{PdO}$ толщиной 30 и 90 нм в относительных единицах на различные концентрации озона в воздухе.

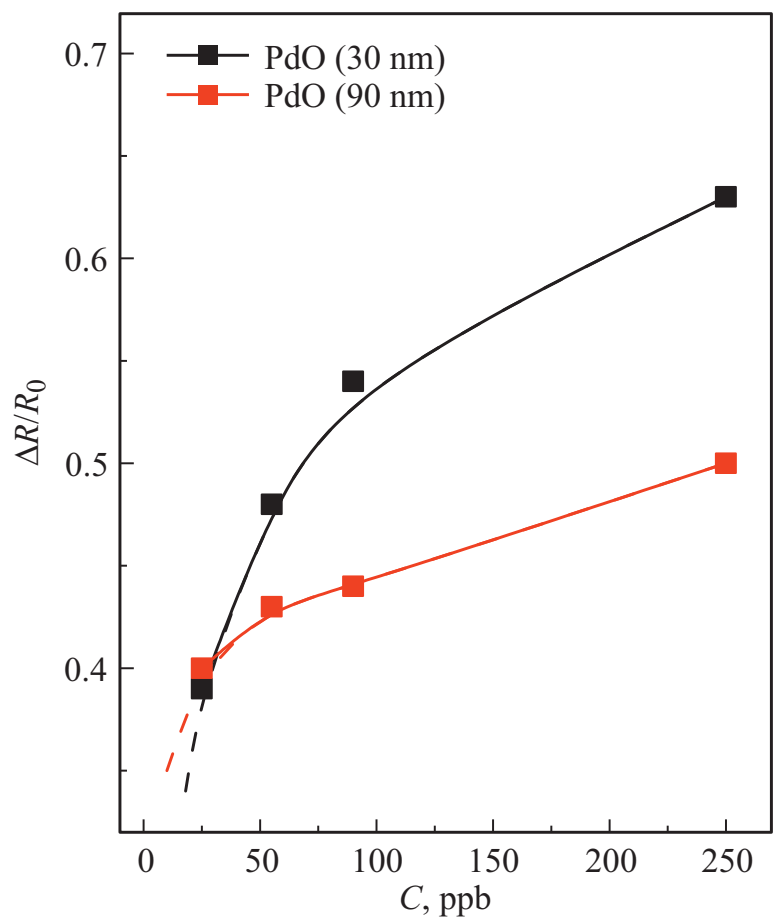

Рис. 5. Зависимость максимальной величины относительного отклика пленок $\mathrm{PdO}$ толщиной 30 и 90 нм от концентрации озона в воздухе. слоя являются недоступными для хемосорбции и шунтируют изменение электропроводности поверхностных областей, а следовательно, ослабляют сенсорный эффект. Именно поэтому в более толстых пленках быстрее происходит насыщение адсорбционной емкости, и они имеют меньший резистивный отклик при относительно больших концентрациях газов.

C другой стороны, экстраполяция графиков $\Delta R / R_{0}-C$ (см. рис. 5) в сторону малых концентраций показывает преимущество более толстой пленки в величине резистивного отклика при концентрациях озона $<25$ ppb.

Таким образом, выявленные особенности сенсорных свойств пленок $\mathrm{PdO}$ разных толщин позволяют установить области их преимущественного применения по концентрации озона в воздухе. Отметим, что сенсоры с высокой чувствительностью к озону низких концентраций (единицы ppb) востребованы в научных исследованиях [11], в том числе для мониторинга фонового содержания озона в чистом атмосферном воздухе. Анализ озона в широком диапазоне концентраций необходим в технологических целях и для обеспечения техники безопасности на производствах.

Анализ литературных данных показал, что минимальные концентрации озона, определяемые с помощью полупроводниковых сенсоров, составляют от единиц до десятков ppb [11-15]. Полученные в настоящей работе результаты соответствуют этим литературным данным. Сенсорные слои $\mathrm{PdO}$, полученные по описанной выше технологии, позволяют проводить детектирование озона в воздухе существенно ниже предельно допустимой концентрации в рабочей зоне.

\section{4. Заключение}

Получены ультратонкие полупроводниковые пленки $\mathrm{PdO}$ для детектирования озона в воздухе путем термического окисления слоев металлического палладия и их последующего окисления на воздухе. Оптимальная температура окислительного отжига сенсорных слоев находится в области $550^{\circ} \mathrm{C}$, что обеспечивает их однофазный состав и не приводит к критической фрагментации пленок.

Фрагментация пленок $\mathrm{PdO}$ при увеличении температуры окислительного отжига, установленная методом ПЭМ, приводит к появлению электрических шумов в процессе резистивных измерений.

Пленки $\mathrm{PdO}$ разной толщины (30 и 90 нм) имеют различные газочувствительные свойства и могут применяться при детектировании озона как в широкой концентрационной области (30 нм), так и в области малых концентраций озона (90 нм), существенно ниже 25 ppb.

\section{Финансирование работы}

Исследование выполнено при поддержке РФФИ (грант № 20-03-00901) и Министерства науки и высшего 
образования РФ в рамках государственного задания вузам в сфере научной деятельности на 2020-2022 годы, проект № FZGU-2020-0036.

\section{Благодарности}

ПЭМ-исследования проведены в Центре коллективного пользования научным оборудованием Воронежского государственного университета (http://ckp.vsu.ru.).

\section{Конфликт интересов}

Авторы заявляют, что у них нет конфликта интересов.

\section{Список литературы}

[1] S.V. Ryabtsev, A.V. Shaposhnick, A.N. Lukin, E.P. Domashevskaya. Sensors Actuators B, 59 (1), 6 (1999). DOI: $10.1016 / \mathrm{S} 0925-4005(99) 00162-8$

[2] S.V. Ryabtsev, V.M. Ievlev, A.M. Samoylov, S.B. Kuschev, S.A. Soldatenko. Thin Sol. Films, 636, 751 (2017). DOI: 10.1016/j.tsf.2017.04.009

[3] S.V. Ryabtsev, A.V. Shaposhnik, A.M. Samoylov, A.A. Sinelnikov, S.A. Soldatenko, S.B. Kuschev, V.M. Ievlev. Doklady Physical Chemistry, 470, 158 (2016). DOI: $10.1134 / \mathrm{S} 0012501616100055$

[4] V.M. Ievlev, S.V. Ryabtsev, A.M. Samoylov, A.V. Shaposhnik, S.B. Kuschev, A.A. Sinelnikov. Sensors Actuators B, 255 (2), 1335 (2018). DOI: 10.1016/j.snb.2017.08.121

[5] S.V. Ryabtsev, D.A.A. Ghareeb, A.A. Sinelnikov, S.Yu. Turishchev, L.A. Obvintseva, A.V. Shaposhnik. Matter and Interphases, 23 (1), 56 (2021). DOI: $10.17308 / \mathrm{kcmf} .2021 .23 / 3303$

[6] J.M. Heras, G. Estiu, L. Viscido. Thin Sol. Films, 188, 165 (1990). DOI: 10.1016/0040-6090(90)90202-O

[7] P.O. Nilsson, M.S. Shivaraman. J. Phys. C: Solid-State Phys., 12, 1423 (1979). DOI: 10.1088/0022-3719/12/7/030

[8] V.Val. Sobolev, D.O. Mordas, V.V. Sobolev. Glass Phys. Chem., 29, 360 (2003). DOI: 10.1023/A:1025116708801

[9] Powder Diffraction File, Alphabetical Index Inorganic Compounds. JCPDS.

[10] Semiconductor Sensors in Physico-Chemical Studies (Handbook of Sensors and Actuators, v. 4), ed. by L.Yu. Kupriyanov (Elsevier, Amsterdam-Lausanna-N.Y.-Oxford-ShannonTokio, 1996). SBN 5-02-001542-3

[11] Л.А. Обвинцева, Т.Б. Шарова, А.К. Аветисов, И.П. Сухарева. Журн. физ. химии, 92 (6), 1099 (2018). L.A. Obvintseva, T.B. Sharova, A.K. Avetisov, I.P. Sukhareva. Russ. J. Phys. Chem. A, 92 (6), 1099 (2018).

DOI: $10.1134 / \mathrm{S} 0036024418060122$

[12] G. Korotcenkov, V. Brinzari, B.K. Cho. Critical Rev. Solid State and Mater. Sci., 43 (2), 83 (2017). DOI: $10.1080 / 10408436.2017 .1287661$

[13] T. Tadashi. In: Chemical Sensor Technology. V. 2. Ed. by T. Seiyama (Tokyo, Koudansha; Amsterdam, Elsevier, 1989) p. 59.

[14] T. Tadashi, T. Hiromasa, S. Tatsuo, H. Kenji. Sensors Actuators B, 25 (1-3), 548 (1995).

[15] Л.А. Обвинцева. Росс. хим. журн., 52 (2), 113 (2008).

Редактор А.Н. Смирнов

\section{Structural and gas-sensitive characteristics of thin semiconductor PdO films of various thickesses during ozone detection}

\author{
S.V. Ryabtsev ${ }^{1}$, D.A.A. Ghareeb ${ }^{1}$, S.Yu. Turishchev' ${ }^{1}$, \\ L.A. Obvintseva ${ }^{2}$, A.V. Shaposhnik ${ }^{3}$, \\ E.P. Domashevskaya ${ }^{1}$ \\ ${ }^{1}$ Voronezh State University, \\ 394018 Voronezh, Russia \\ ${ }^{2}$ Russian State University named after A.N. Kosygin, \\ 119071 Moscow, Russia \\ ${ }^{3}$ Voronezh State Agricultural University, \\ 394087 Voronezh, Russia
}

Abstract PdO films were obtained by thermal deposition of palladium metal with a thickness of 30 and $90 \mathrm{~nm}$, followed by its oxidation in air at different temperatures. PdO oxide films are characterized by transmission electron microscopy (TEM) and fast electron diffraction (DBE). Data on the semiconductor properties and gas sensitivity to different concentrations of ozone in the air are obtained. The optimal temperature conditions for the oxidation of the films are established, which ensure their uniform phase composition and the absence of electrical noise during the detection of gases. The mechanism of the appearance of electrical noise in ultrathin films associated with their fragmentation during oxidative annealing is proposed and justified. The possibility of detecting ozone impurities in the air below the maximum permissible concentration (MPC) by $\mathrm{PdO}$ semiconductor films is shown. 